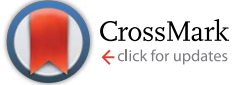

Cite this: RSC Adv., 2016, 6, 86151

Received 15th June 2016

Accepted 22nd August 2016

DOI: $10.1039 / c 6 r a 15545 f$

www.rsc.org/advances

\section{Antimicrobial activities of phosphonium containing polynorbornenes $\uparrow$}

\author{
N. Ceren Süer, ${ }^{a}$ Ceren Demir, ${ }^{a}$ Nihan A. Ünübol, ${ }^{b}$ Özlem Yalçın, ${ }^{c}$ Tanıl Kocagöz $^{\star b}$ \\ and Tarik Eren*a
}

In this study, amphiphilic polyoxanorbornene with different alkyl and aromatic phosphonium side chains was synthesized. The biological activities of these polymers were determined by the minimal inhibitory concentration (MIC) against E. coli, S. aureus, M. tuberculosis and the yeast C. albicans, and cytotoxicity studies on red blood cells were performed. A series of polymers with different alkyl and aromatic substituents (methyl, ethyl, tripropyl, tert-butyl, phenyl, and tris 4-methoxyphenyl) and two types different molecular weight, $3000 \mathrm{~g} \mathrm{~mol}^{-1}$ and $10000 \mathrm{~g} \mathrm{~mol}^{-1}$, were prepared. It was observed that the biological activity of the polymers with aromatic group substituents had an MIC of 16, 8, 64 and $128 \mu \mathrm{g}$ $\mathrm{mL}^{-1}$ against $E$. coli, S. aureus, M. tuberculosis and C. albicans, respectively, while those with nonaromatic carbons had a higher MIC compared to those with aromatic carbons. The aromaticity of the repeat unit had impressive effects on hemolytic activities as well. Zeta potential measurements of $E$. coli incubated with active and inactive polymer concentration revealed a relationship between the MIC and membrane surface charge density. Polymers bearing aromatic groups killed the bacteria with widespread damage after the polymers, holding the threshold concentration, were added to the bacteria.

\section{Introduction}

The evolution of antibiotic-resistant microorganisms is one of the most threatening global problem. ${ }^{1-4}$ In particular, the appearance of new pathogens and growing antibiotic resistant have spread out the research for new antibiotics. During the same period, new pathogens have appeared and antibioticresistant strains have evolved. The war against microbes is far from over. ${ }^{5}$ Hospitals by their very nature contain large numbers of sick people, many of whom carry infectious agents that can spread by direct or indirect contact. Therefore, hospital surfaces are subject to constant contamination events as patients and staff could move from one place to another.

Nowadays, hospital acquired, or nosocomial, infections have gradually expanded all over the world and the trend is increasing. Approximately two million people acquired hospital infections in United States and 99000 died from those infections. ${ }^{6}$ Host-defence peptides (HDPs) and their synthetic mimics have prompted extensive studies for potential therapeutic applications. ${ }^{7,8}$ The exploration of HDPs and their chemical analogues as an antibacterial agent is currently

\footnotetext{
a Department of Chemistry, Yildiz Technical University, Davutpasa Campus, 34220, Esenler, Istanbul, Turkey.E-mail: teren@yildiz.edu.tr; erentari@gmail.com

${ }^{b}$ Department of Medical Microbiology, Acibadem University, Kerem Aydinlar Campus, 34752, Atasehir, Istanbul, Turkey

${ }^{c}$ School of Medicine, Koc University, Sariyer Campus, 34450 Sariyer, Istanbul, Turkey

$\dagger$ Electronic supplementary information (ESI) available. See DOI: 10.1039/c6ra15545f
}

attracting interest for potential therapeutic applications. ${ }^{9}$ The distribution of hydrophilic (cationic) and hydrophobic groups in the peptide backbone is favorable for the amphiphilic structures; moreover, it enhance the interaction with the bacterial surface, which are one of the fundamental mechanisms of action. However, there are some drawbacks of using HDPs and their synthetic analogues as antimicrobial agents such as (i) the production of these types of compounds is extremely costly and (ii) long range resistance to enzymatic degradation for their possible usage in therapeutic applications. ${ }^{10,11}$ Synthetic cationic polymers have emerged as promising candidates for further development as antimicrobial agents. ${ }^{12-19}$ This class of polymeric compounds is rather inexpensive with respect to the HDPs and resistant to physiological conditions. There are several reported synthetic polymers that can display selectivity, i.e., prokaryote-specific toxicity. ${ }^{\mathbf{1 2 , 1 3 , 2 0 - 2 2}}$ Selectivity has typically been assigned by the hemolytic activity over antibacterial activity. Basically, antimicrobial cationic polymers and peptides target the phospholipid membranes of bacterial cells. Phospholipid bilayer of both Gram-positive and Gram-negative bacterial cell membranes predominantly consist of anionic phospholipid head groups, whereas those found on eukaryotic cells are neutral. These negatively charged outer surfaces enhance the electrostatic interactions for the cationic peptides and polymers with bacteria, thus allowing them to implement their antibacterial effect. Despite this action, hydrophobicity also plays a role in the enhancement of activity and toxicity. Thus, to improve the resistance to HDPs and 
cationic polymers, bacteria will require more complex changes including alteration of the cell membrane.

Biocidal cationic polymers possessing quaternary ammonium and phosphonium salts have better antibacterial activities compared to their small biocidal counterparts. ${ }^{23}$ However, there are fewer studies on phosphonium based antibacterial polymers in the literature compared to ammonium salt derivatives. Tan and his group obtained phosphonium salts by reacting graphite surface with different concentrations of TTP (tetradecyl triphenyl phosphonium bromide). ${ }^{24}$ The antibacterial activity of graphite that contains $33.7 \%$ phosphonium salt was determined to be $580 \mathrm{mg} \mathrm{L}^{-1}$ and $285 \mathrm{mg} \mathrm{L}^{-1}$ against $E$. coli and $S$. aureus. They also used montmorillonite instead of graphite and added phosphonium salts to Na-montmorillonite layers using an ion exchange method. ${ }^{25}$ They found that phosphonium-containing montmorillonites are thermally more stable than ammonium-containing montmorillonites and their MIC values are $150 \mathrm{mg} \mathrm{L}^{-1}$ and $50 \mathrm{mg} \mathrm{L}^{-1}$ against $E$. coli and $S$. aureus. Guo and his group obtained different concentrations of water soluble chitosan that contains different concentrations of quaternary phosphonium salt (3.6\% and $4.2 \%) .{ }^{26}$ The toxicity of the obtained polymers was examined on L929 cells and no toxic effects were found. Endo and Kanazawa synthesized polymers using the monomer 4-vinyl benzyl phosphonium chloride as a phosphonium salt, which can be used for dental fillers and examined their antibacterial activity. ${ }^{27}$ The activity of polymers was measured against Streptococcus mutans (S. mutans) and it was found that at $10 \mu \mathrm{mol} \mathrm{mL} \mathrm{m}^{-1}$ within 24 hours, the polymers showed higher activity compared to poly (methylmethacrylate).

The ROMP (ring opening metathesis polymerization) method is one of the techniques used for controlled polymerization system. Norbornene backbone and functional group tolerance provide the ROMP in the preparation of biologically active well-defined polymeric materials. ${ }^{28-30}$ Recently, a large number of ROMP-based antibacterial polymers were synthesized. $^{31,32}$ Coughlin and Tew synthesized polynorbornene derivatives of ammonium salts with ROMP method and evaluated their antibacterial activity. It was seen that when the hydrophobic parts on the polymer chain was increased, the antibacterial activity and toxicity increased as well. ${ }^{12}$ In another study, pyridine salts were polymerized by the ROMP method and assessed for their antibacterial and hemolytic activity, and it was found that ethyl bromide based salt has the highest hemolytic activity. ${ }^{22}$ The structure-property relationship of those polymers might provide a new design for the biocidal polymer architecture. These polymers can also be synthesized on a large scale. One-pot synthesis with a control of the backbone is particularly attractive for the use of a new generation of biocidal polymeric antibiotics. ${ }^{33,34}$

Herein, we present phosphonium containing antibacterial polymers that can be considered a subgroup of biocidal polymers. In the literature, there are no studies of phosphoniumcontaining polymers synthesized with ROMP, so we report the characterization and antibacterial evaluation of cationic charged phosphonium-containing polyelectrolytes synthesized by ROMP, which can be an alternative for cationic based peptidomimic. Herein, quaternary phosphonium functionality
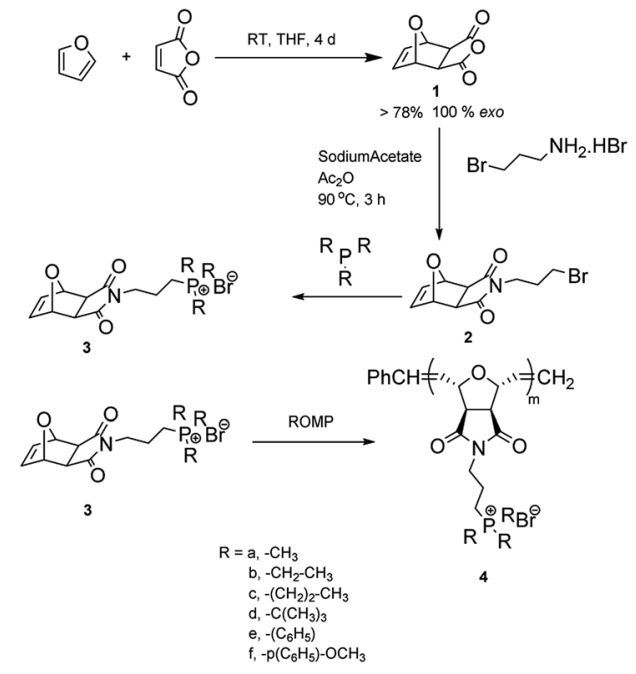

Scheme 1 Monomer and polymers based on oxanorbornene derivatives.

attached to oxanorbornene monomers was then polymerized using a Grubbs' catalyst, as shown in Scheme 1.

\section{Experimental section}

All experimental procedures, including monomer and polymer synthesis, all spectroscopic data, as well as the biological assays, are included in the ESI. $\dagger$

\section{Results and discussion}

\subsection{Monomer synthesis}

Phosphonium bearing monomer synthesis started with a DielsAlder reaction between maleic anhydride and furan to yield product $1{ }^{35}$ Treatment of 1 with 3-bromopropylamine hydrobromide resulted in imide transformation in the presence of NaOAc/acetic anhydride mixture to obtain bromoderivative $2 .^{36}$ The salts, $\mathbf{3 a}-\mathbf{f}$, were synthesized by nucleophilic $\left(\mathrm{S}_{\mathrm{N}} 2\right)$ addition of respective phosphine reagents to compound 2, as shown in Scheme 1 . The average yield of all the compounds was between $11 \%$ and $90 \%$; tert-butyl (3d) and triphenyl phosphine (3e) were the yield reducing step due to steric effects. All the monomers were typically creamy to pale yellow crystals. All the salts were hygroscopic and soluble in water except monomers $\mathbf{3 e}$ and $\mathbf{3 f}$. These monomers were analyzed by NMR spectroscopy. ${ }^{37,38}$ The ${ }^{31} \mathrm{P}\left\{{ }^{1} \mathrm{H}\right\}$ NMR spectra of the salts exhibited a singlet between $\delta 20.01$ and $49.91 \mathrm{ppm}$. Monitoring the reactions was very straightforward as the used phosphine reagents showed signals in the $\delta-6$ to $-60 \mathrm{ppm}$ range. In addition, traces of phosphine oxide side products for the ethyl (3b), phenyl (3e) and methoxyphenyl (3f) salts at $\delta 65.11,29.21$, and $27.03 \mathrm{ppm}$ were observed. The presence of side products might result from the sensitivity of phosphines to oxidation and precaution and exceptional care in handling should be taken into consideration while the application in the synthesis. These side products can be eliminated easily by successive washing of the residue with the appropriate solvents (usually THF was sufficient for this 
purpose). Proton and carbon-13 NMR spectra of 3a-f are also assigned (ESI Fig. S1-S14 $\dagger$ ). The characteristic signals of oxanorbornene protons and carbons appeared at $\delta 6.57,5.15$ and $2.98 \mathrm{ppm}$ in the ${ }^{1} \mathrm{H}$ NMR spectra and $\delta 176.65,136.41,80.45$ and 47.21 in the ${ }^{13} \mathrm{C}$ NMR spectra. The protons of the substituent neighbour to the phosphor can be observed as a doublet due to the strong phosphorous-hydrogen coupling. For example, methyl groups in $3 a$ give rise to a doublet at $\delta 1.75 \mathrm{ppm}$ with the characteristic ${ }^{2} J$ coupling of approximately $14.3 \mathrm{~Hz}$. While the number of $\left(-\mathrm{CH}_{2}-\right)$ groups increases, i.e. $3 \mathbf{a}-\mathbf{c}$, the shift of the methyl group $\left(-\mathrm{CH}_{3}\right)$ at the end of the alkyl functional group moves to a higher magnetic field. In addition, the typical doublet shifts due to hetero-coupling between the C-nucleus and the P-nucleus was also observed in ${ }^{13} \mathrm{C} N M R \cdot{ }^{39}$ As an example, verification of the phosphorus-carbon bond in 3a was observed as large ${ }^{1} J$ coupling $(85.8 \mathrm{~Hz})$ in the doublet of methyl carbons $\left(\mathrm{CH}_{3}-\mathrm{P}^{+}\right)$at $\delta 7.22 \mathrm{ppm}$ (Fig. $\left.\mathrm{S} 4 \dagger\right)$. Methylene carbons next to the phosphonium cation $\left(-\mathrm{CH}_{2}-\mathrm{P}^{+}\right)$were observed at $\delta 20.02 \mathrm{ppm}$ with a ${ }^{1} J$ coupling as $50.9 \mathrm{~Hz}$. In addition, ${ }^{2} J$ coupling was also observed for methylene carbons $\left(-\mathrm{CH}_{2}-\mathrm{CH}_{2}-\right.$ $\left.\mathrm{P}^{+}\right)$at $\delta 20.45 \mathrm{ppm}$ with $J=5.6 \mathrm{~Hz}$. Longer range ${ }^{2} J$ and ${ }^{3} J$ couplings were also reliable through phosphorus-carbon bond formation.

\subsection{Polymer synthesis}

The polymers, 4a-f, were synthesized from the respective monomers 3a-f and used to evaluate the influence of the alkyl/ aromatic side chain on the antibacterial and hemolytic activity of the polymers. Monomers 3a-f were polymerized using Grubbs' third generation catalyst in 2,2,2-trifluoroethanol, $N, N$ dimethylformamide or dichloromethane at room temperature. A targeted number average molecular weight $\left(M_{\mathrm{n}}\right)$ of 3000 or $10000 \mathrm{~g} \mathrm{~mol}^{-1}$ was applied using the proper monomer to catalyst concentration. After work up, complete conversion of polymerization was observed by the total disappearance of the monomer olefin proton peaks at $\delta$ 6.0-6.3 ppm and the appearance of the polymer backbone double bond protons as cis or trans signals at $\delta$ 5.1-5.6 ppm (Fig. S15-S20 $\dagger$ ). The appearance of vinylic hydrogens obtained by the ROMP pathway resulted in both cis- and trans-double bond formation and the integration of these two signals in ${ }^{1} \mathrm{H}$ NMR indicates the relative cis/trans ratio in the polymer backbone. The resulting homopolymers contained $\sim 55-65 \%$ trans residue. In addition, long range coupling of phosphorus-carbon linkage was not observed due to the diminishing resolution of the polymeric system. However, the large ${ }^{1} J$ coupling of the para-aryl carbon to the phosphonium cation (present in $\mathbf{4 d}$ and $\mathbf{4 f}$ ) was still evident in the doublet at $\delta 118.03 \mathrm{ppm}\left({ }^{1} J_{\mathrm{CP}}=86.2 \mathrm{~Hz}\right)$. End group analysis of the purified polymer was applied to calculate $M_{\mathrm{n}}$ in comparison to the assumed molecular weight using ${ }^{1} \mathrm{H}$ NMR techniques. $^{22}$ The phenyl end group connected to the original carbene moiety from the catalyst is visible at $c a . \delta \sim 7.20-7.50$ ppm. Integration of the $\left(-\mathrm{CH}=\mathrm{CH}_{\text {cis,trans }}{ }^{-}\right)$peaks relative to the styrenic end group from the Grubbs' catalyst in the ${ }^{1} \mathrm{H}$ NMR spectra of the polymer indicated the degree of polymerization. For example, theoretical molecular weight, $3000 \mathrm{~g} \mathrm{~mol}^{-1}$, of polymer $4 \mathbf{a}$ has a degree of polymerization of 8 , which compares well with the calculated value of 9 (Table 1). However, it is well known that integration values of the ${ }^{1} \mathrm{H}$ NMR peak refer to the solvent used for the analysis in NMR. The actual integration values of NMR peaks can be obtained correctly only if the micelle formation does not occur in the NMR solvent. ${ }^{40}$ Because of these reasons, some deviation from the theoretical values could be observed. GPC measurements of all the polymers could not be carried out as $4 d \_10 k, 4 e \_3 k, 4 e \_10 k, 4 f \_3 k$, and 4f_10k are not soluble in PBS buffer solution. The theoretical $M_{\mathrm{n}}$ and observed $M_{\mathrm{n}}$ values by GPC do not comply well with each other (Table 1). GPC calibration with linear, non-ionic poly(ethylene oxide) standards resulted in different hydrodynamic volumes with respect to the cationic phosphonium polymers. However, the experimentally determined $M_{\mathrm{w}} / M_{\mathrm{n}}$ for the polymers, as shown in Table 1, indicates that a controlled and well-defined system was achieved by the ROMP method with the polydispersity index (PDI) of $\sim 1$.

\subsection{Biological activity of polymers}

The activity of all polymers was explored against E. coli, M. tuberculosis (Gram-negative bacteria), S. aureus (Gram-positive bacteria) and $C$. albicans (fungus) as representative microbial communities. The biocidal activity obtained for these homopolymers is reported in Table 2. Polymer solutions were prepared by dissolution in water (4a, $\mathbf{4 b}, \mathbf{4 c}$ and $\mathbf{4 d} \_\mathbf{3 k}$ ) or DMSO (4d_10k, 4e and 4f) and further diluted with buffer. The results confirm that the phosphonium polymers with aromatic substituent (4e and $\mathbf{4 f}$ ) have better antibacterial activities than the alkyl substituent derivatives (4a-4d). The MICs of all the polymers against fungi are generally low $\left(\geq 128 \mu \mathrm{g} \mathrm{mL} \mathrm{mL}^{-1}\right)$. Increase in the alkyl substituents from methyl to tert-butyl (4a4d) alone decreases the MICs against Gram-positive S. aureus but not against Gram-negative $E$. coli and $M$. tuberculosis. It should be mentioned that M. tuberculosis is related more to Gram-negative than to Gram-positive bacteria as revealed by the

Table 1 Summary of the theoretical $M_{n}$, measured $M_{n}$ and $M_{w} / M_{n}$ values for the homopolymers $4 a-f$

\begin{tabular}{|c|c|c|c|c|}
\hline Polymer & $M_{\mathrm{n}, \text { the }}{ }^{a}$ & $M_{\mathrm{n}, \mathrm{NMR}}{ }^{b}$ & $M_{\mathrm{n}(\mathrm{ASEC})^{c}}$ & $M_{\mathrm{w}} / M_{\mathrm{n}}{ }^{c}$ \\
\hline 4a_3k & 3000 & 3864 & 6306 & 1.059 \\
\hline 4a_10k & 10000 & 9430 & 38137 & 1.102 \\
\hline $4 b \_3 k$ & 3000 & 4475 & 7234 & 1.057 \\
\hline 4b_10k & 10000 & 14028 & 14298 & 1.049 \\
\hline $4 c_{-} 3 k$ & 3000 & 4053 & 8869 & 1.057 \\
\hline $4 c_{-} \_10 \mathrm{k}$ & 10000 & 15534 & 17277 & 1.008 \\
\hline 4d_3k & 3000 & 3698 & 30911 & 1.06 \\
\hline 4d_10k & 10000 & n.d. & n.d. & n.d. \\
\hline $4 e_{-} 3 k$ & 3000 & n.d. & n.d. & n.d. \\
\hline $4 e_{-} \_10 k$ & 10000 & n.d. & n.d. & n.d. \\
\hline 4f_3k & 3000 & n.d. & n.d. & n.d. \\
\hline 4f_10k & 10000 & n.d. & n.d. & n.d. \\
\hline
\end{tabular}

${ }^{a} M_{\mathrm{n}, \mathrm{the}}=$ mass of monomer $\mathrm{g} \mathrm{mol}^{-1}$ of initiator. ${ }^{b}$ As determined by ${ }^{1} \mathrm{H}$ NMR spectroscopy. ${ }^{c}$ As determined by aqueous size exclusion chromatography in buffer $0.25 \mathrm{M} \mathrm{NaBr}$. System was calibrated with narrow molecular mass poly(ethylene oxide) standards. 
Table 2 Antimicrobial and hemolytic activities of polymers

\begin{tabular}{|c|c|c|c|c|c|}
\hline Polymer & \multicolumn{4}{|c|}{$\operatorname{MIC}^{a}\left(\mu \mathrm{g} \mathrm{mL}^{-1}\right)$} & $\mathrm{HC}_{50}{ }^{b}$ (\% hemolysis) \\
\hline 4a_10k & 512 & 512 & 512 & $>512$ & 1 \\
\hline 4b_3k & $>512$ & 64 & 128 & $>512$ & 2 \\
\hline $4 b \_10 k$ & $>512$ & $>512$ & $>512$ & $>512$ & 2 \\
\hline 4d_3k & $>512$ & 128 & 128 & 128 & 4 \\
\hline 4d_10k & 512 & 32 & 128 & 256 & 2 \\
\hline $4 e_{-} 3 k$ & 16 & 8 & 128 & 64 & 99 \\
\hline $4 e_{-} 10 k$ & 32 & 16 & 128 & 512 & $>100$ \\
\hline 4f_3k & 32 & 8 & 128 & 64 & 85 \\
\hline 4f_10k & 64 & 8 & 128 & 128 & 46 \\
\hline
\end{tabular}

${ }^{a}$ Inhibitory activity towards bacterial growth of E. coli, S. aureus and M. tuberculosis bacteria and growth of C. albicans fungi (MIC ${ }_{90}=$ minimal inhibitory concentration preventing $90 \%$ bacterial or fungi growth) and hemolytic activity towards red blood cells $\left(\mathrm{HC}_{50}=\mathrm{concentration} \mathrm{lysing}\right.$ $50 \%$ of blood cells). ${ }^{b}$ Hemolysis caused by $512 \mu \mathrm{g} \mathrm{mL} \mathrm{m}^{-1}$ polymer concentration.

sharing comparatively more genes for energy production and conversion with Gram-negative bacteria than with Grampositive bacteria. ${ }^{41}$ The architecture of the entire cell-wall of M. tuberculosis mainly consist of a peptidoglycan layer with a phosphodiester linkage, which in turn is attached to mycolic acids. ${ }^{42,43}$

Mycolic acids are long fatty acids found in the cell membrane and provide a lipid barrier that enhances the resistance to chemical damage and dehydration and prevent the activity of common antibiotics. All the polymer series were inactive against $M$. tuberculosis, except the MIC of polymer 4e_3k and 4f_3k containing aromatic units was $64 \mu \mathrm{g} \mathrm{mL}^{-1}$. However, more rigid substituents on the polymer structure (entries 4e and 4f, Table 2) have dramatically lower MICs against $E$. coli and $S$. aureus $\left(8-64 \mu \mathrm{g} \mathrm{mL}{ }^{-1}\right)$, which are comparable to natural host defence peptide magainin MSI-78 possessing MIC of $12.5 \mu \mathrm{g} \mathrm{mL}{ }^{-1} \cdot{ }^{12}$ Polymer 4b_3k shows a much lower MIC compared to $\mathbf{4 b} \_\mathbf{1 0 k}$ against $S$. aureus. Polymer 4d_10k, containing the tert-butyl substituent, has an MIC of 512 $\mu \mathrm{g} \mathrm{mL} \mathrm{m}^{-1}$ against E. coli compared to $32 \mu \mathrm{g} \mathrm{mL} \mathrm{m}^{-1}$ for $S$. aureus, resulting in a polymer selectivity (one bacterial type over another); it was 16 times more active against $S$. aureus than against $E$. coli. Such bacteria type selectivity was previously observed by Lienkamp et al. ${ }^{13}$ Herein, the reason for the lower biocidal activity to $E$. coli over $S$. aureus is unclear and further studies should have been applied to understand the mechanism. One possible explanation is that $E$. coli has a thin peptidoglycan cell wall sandwiched between an outer and inner membrane. Despite this, S. aureus has 20-80 nm thick peptidoglycan layers surrounding plasma membrane bearing a single phospholipid bilayer. Therefore, the biocidal polymers need to fracture two membranes to kill the $E$. coli envelope, whereas they can diffuse through the peptidoglycan layers of $S$. aureus and result in the destruction of its plasma membrane more efficiently. The weak interaction with phospholipid membrane of $E$. coli and strong adhesion to phospholipid membrane of $S$. aureus could be a reason for the higher biocidal activity against $S$. aureus than $E$. coli.

The amphiphilicity of the ROMP polymers is an important factor for the selectivity and activity. ${ }^{12,13}$ Increasing the hydrophobicity of the polymer structure enhances the interaction between the phospholipid bilayer and result in an enhancement in activity. However, excessive hydrophobicity in the polymer backbone favors cytotoxicity and also might precipitate in the test conditions. It was determined that incorporation of the aromatic ring to the polymer backbone, $\mathbf{4 e}$ and $\mathbf{4 f}$, has a significant effect on biocidal activity. It was hypothesized that the respective $\pi$ electron density and rigidity of the aromatic ring would destabilize the cell membrane for tuning the activity for 4e and 4f. An increase in the aromaticity of the polymers enhances the various $\pi$ interactions between the polymers and cell membrane. ${ }^{44}$ However, phenyl rings with a highly hydrophobic rigid structure might be the key parameter here for better interaction and destabilization of the bacterial membrane and leakage of the cell.

Overall, we can conclude that adding alkyl-based hydrophobicity, i.e. methyl to tert-butyl (4a-4d), improves activity, even though polymers bearing aromatic groups show better biocidal activity than aliphatic groups.

\subsection{Hemolytic concentration}

The hemolytic activity $\left(\mathrm{HC}_{50}\right)$ of the polymers toward red blood cells (RBCs) was tested, as described previously. ${ }^{12} \mathrm{HC}_{50} / \mathrm{MIC}_{90}$ ratio is defined as the antibacterial selectivity. As can be seen from Table 2, the polymer with the highest selectivity for bacterial over mammalian cells is $\mathbf{4 d} \_\mathbf{1 0 k}$, with a good selectivity of $>30$ for $S$. aureus. Moreover, magainin, one of the natural host defense peptides, has a selectivity of $10 .{ }^{45}$ From $4 a$ to $4 \mathbf{f}$, the polymers became strongly hemolytic. Their high hydrophilicity prevents $\mathbf{4 a - 4 d}$ from the activity against RBCs; however, polymers having hydrophobic rigid analogous (4e-4f) cause significant hemolysis. Polymer possessing the aliphatic 
hydrophobic group was altered from a methyl group, 4a, to a tert butyl, 4d, and resulted in $\sim 1 \%$ hemolysis at $250 \mu \mathrm{g} \mathrm{mL}$ polymer concentration. An overly aromatic substituent (4e-4f) enhances the membrane interaction and as a result, is very hemolytic. For these series of polymers, they start to become more hemolytic $\left(\mathrm{HC}_{50} \leq 250 \mu \mathrm{g} \mathrm{mL}^{-1}\right)$. It was also determined that the nature of $\pi$-rich (4f) aromatic rings, methoxy substituents on the phenyl ring, did not have any significant difference on hemolysis data with respect to phenyl substituents (4e). It seems that the polymers have ideal facial amphiphicities and rigidity to destroy the bacterial and RBCs membrane.

The effect of molecular weight on biocidal activities was also examined by $3000 \mathrm{~g} \mathrm{~mol}^{-1}$ and $10000 \mathrm{~g} \mathrm{~mol}^{-1}$ for the polymer 4a-4f. The molecular weights did not result in substantial deviation in activities and activity was described as mass/ volume rather than molarity. ${ }^{22}$ It can be expected that high molecular weight polymers will be more active with a lower molar concentrations. We assume that polymers with higher molecular weight could then get stuck on the membrane surface and result in an improvement of the electrostatic and hydrophobic interactions with the phospholipid bilayer of the cell membrane. However, compared to their $M_{\mathrm{n}}=3000 \mathrm{~g} \mathrm{~mol}^{-1}$ analogues of $4 \mathbf{e}$ and $\mathbf{4 f}$, these polymers holding $M_{\mathrm{n}}=10000 \mathrm{~g}$ $\mathrm{mol}^{-1}$ were slightly less active against E. coli. More notably, biological data for $\mathbf{4 d}$ showed an increase in activity against $S$. aureus (from $128 \mu \mathrm{g} \mathrm{mL} \mathrm{m}^{-1}$ to $64 \mu \mathrm{g} \mathrm{mL}^{-1}$ ) with an increase in molecular weight.

\subsection{Biophysical characterization}

Several mechanisms, such as carpet, barrel-stave, and toroidal pore, have been suggested for the action of host-defense peptides and their synthetic analogous against bacteria and RBCs. ${ }^{8}$ Facially amphiphilic, described as the hydrophilic and hydrophobic side chain, enables the molecules to penetrate the cell membranes. This type of interaction locally changes the membrane association, causing pore formation, and the holes in the phospholipid bilayer result in crumbling of the cell membrane and the death of the cell. In general, antimicrobial peptides and polymers possess positively charged hydrophilic groups that enhance electrostatic interaction with the negatively charged bacterial cell membrane, whereas their hydrophobic groups interact with the phospholipid tail groups, resulting in membrane permeation and disruption. ${ }^{46}$ This type of mechanism does not request a specific receptor-like cell target for the biocidal activity. Facial amphiphilicity could also provide selectivity by becoming less toxic towards mammalian cells. It is also argued that this type of nonspecific interaction with the bacteria membrane might diminish the bacterial resistance build-up, as associated to traditional antibiotics. ${ }^{8}$

An important development step in synthetic mimic of antimicrobial peptides design was to completely exclude the helical secondary structure. DeGrado and Tew developed aryl-amide based molecules with a phenylene-ethylene backbone with a primary amine salt to obtain facially amphiphilic molecules. ${ }^{47}$ The rigidity of aryl-amide backbone induced a linear facially amphiphilic confirmation that enhances the action upon contact with the cell membrane. However, Kuroda and DeGrado showed that the rigid nature of the backbone and the presence of aromatic groups were not crucial for obtaining the selectivities for bacteria over RBCs. $^{20}$ It was declared that facial amphiphilicity on the monomer level was an important parameter. Tew and coworkers observed that aromatic functionality provides better biocidal efficiency than polymers bearing aliphatic groups. ${ }^{\mathbf{4 8 , 4 9}}$ It was proposed that aromatic functional groups may play a special role, beyond their general hydrophobicity. Despite these observations, each molecule should be considered separately and other parameters, such as molarity, solubility in buffer media, and conformations, should also be taken into consideration while the mechanism in action is described.

Biophysical techniques, such as AFM, fluorescence spectroscopy, confocal microscopy, and solid state NMR, are common techniques to investigate the mechanism and mode of action of antimicrobial substances. ${ }^{45}$ Analysis of the polymer interactions at the membrane level is one of the important parameters to understand the antimicrobial mechanism. In this study, the mechanisms adopted by active and inactive polymers $(\mathbf{4 b}, \mathbf{4 e}$ and $\mathbf{4 f})$ in disrupting the Gram negative $E$. coli bacterial envelope were investigated. Polymer bearing a positive charge with phosphonium groups enhances the electrostatic interaction with the anionic bacteria surface, whereas the hydrophobic groups, basically aromatic ones, support polymer insertion into the phospholipid bilayer of the cell membrane. We applied zeta potential measurements to establish a correlation between MIC and surface charge distribution of bacterial membrane. Herein, $E$. coli was incubated with active/inactive polymer concentration. As shown in Table 3, E. coli, in the absence of either polymer, displayed a zeta potential of $0.00161 \pm 0.0002 \mathrm{mV}$. Relative to $E$. coli, polymers are considerably more basic and positively charged except 4e_3k in the buffer conditions used at the zeta experiment. Upon the addition of the active polymer 4e_3k and $\mathbf{4 f} \_3 \mathbf{k}$, E. coli zeta potential values decreased and then stabilized at approximately $-\mathbf{1 7 . 1} \mathrm{mV}$ and $-\mathbf{1 5 . 1} \mathrm{mV}$, respectively. The interaction of $\mathbf{4} \mathbf{e} \_3 \mathbf{k}$ with $E$. coli can be attributed to hydrophobic interactions associated with membrane disruption. ${ }^{50}$ The decrease in zeta potential may be explained by taking the release of negatively charged phospholipids, such as

Table 3 Effect of polymer treatment on the zeta potential properties of $E$. coli ${ }^{a}$

\begin{tabular}{|c|c|}
\hline Polymer & Zeta potential $(\mathrm{mV})$ \\
\hline 4b_3k & $0.048 \pm 0.01$ \\
\hline 4f_3k & $-6.59 \pm 0.1$ \\
\hline $4 e_{-} 3 k$ & $7.98 \pm 0.1$ \\
\hline E. coli & $0.00161 \pm 0.0002$ \\
\hline E. coli/DMSO & $0.0437 \pm 3.0$ \\
\hline E. coli/4e_3k & $-17.1 \pm 0.1$ \\
\hline E. coli/4f_3k & $-15.1 \pm 0.1$ \\
\hline E. coli/4b_3k & $-0.0303 \pm 0.01$ \\
\hline
\end{tabular}


cardiolipin and phosphatidylethanolamine from the E. coli membrane disruption, into account. However, 4f_3k interacts more strongly with the $E$. coli membrane by a hydrophobic interaction and also with the lipid head groups by electrostatic forces.

In contrast, addition of the inactive polymer $\mathbf{4 b} \mathbf{b} 3 \mathbf{k}$ indicated a slight decrease in the zeta potential value to $-0.0303 \mathrm{mV}$. Our results with $\mathbf{4 b}$ _3k suggested that this polymer was not embedded or weakly partitioned to the membrane bilayer and was not effective in destabilizing the bacterial membrane. We believed that the membranes ultimately equilibrate with the polymer solutions. It is also possible that $\mathbf{4 b} \mathbf{b} \mathbf{3} \mathbf{k}$ can be adsorbed (reversibly) by the membrane, but does not intercalate. The effect of DMSO that is used to solubilize the $4 \mathbf{4} \_3 \mathbf{k}$ and $\mathbf{4 f} \_3 \mathbf{k}$ in buffer was also tested and a minor change in the zeta potential value of $E$. coli was observed.

Electrostatic properties of the $E$. coli surface after the incubation of respective polymers indicated the significant differences in zeta potential values. Each amphiphilic molecules have different electrostatic and hydrophobic interactions with the cell membrane. Based on the result in this study, the adoption of a carpet-like or detergent-like mechanism by the two polymer 4e and $4 \mathbf{f}$ investigated here appears to be likely. Other factors, such as polymer conformation in the buffer or the role of the membrane potential cannot be excluded while describing the brief mechanism. However, further biophysical techniques should have been used to analyse the membrane in action.

\section{Conclusions}

Using ring-opening metathesis polymerization techniques, phosphonium based cationic polymers were obtained. By careful tuning of the overall hydrophobicity/aromaticity and charge density of these molecules, the inactive and active properties were determined. The effects of certain design features, such as charge, hydrophobicity and aromaticity, on the properties across the polymer series, can be understood.

When the alkyl substituent methyl, ethyl propyl and tertbutyl are used, the polymers are weakly or moderately active (and not hemolytic), but when the aromatic based alkyl substituent are used, the polymers are quite potent (and generally toxic). A rigid backbone against to nonaromatic groups enhances the antibacterial activity. This suggests that other design parameters, such as overall hydrophobicity and cationic charge, have a less significant impact on the biocidal activity. Understanding these design principles encourage us to develop new antimicrobial polymers possessing aromatic groups on their structure. We anticipate that future research towards the new design selective polymer will make significant contributions to a new generation of antibiotics.

\section{Acknowledgements}

This study was supported by the Scientific and Technological Research Council of Turkey (TUBITAK) project no. 113S355. Support from the COST Action CM1302 SIPs is also gratefully acknowledged.

\section{Notes and references}

1 H. F. Chambers and F. R. DeLeo, Nat. Rev. Microbiol., 2009, 7, 629-641.

2 S. Binder, A. M. Levitt, J. J. Sacks and J. M. Hughes, Science, 1999, 284, 1311-1313.

3 A. Opar, Nat. Rev. Drug Discovery, 2007, 6, 943-944.

4 R. A. Weinstein, Emerging Infect. Dis., 2001, 7, 188.

5 H. W. Boucher, G. H. Talbot, J. S. Bradley, J. E. Edwards, D. Gilbert, L. B. Rice, M. Scheld, B. Spellberg and J. Bartlett, Clin. Infect. Dis., 2009, 48, 1-12.

6 R. M. Klevens, J. R. Edwards, C. L. Richards Jr, T. C. Horan, R. P. Gaynes, D. A. Pollock and D. M. Cardo, Public Health Rep., 2007, 160-166.

7 R. E. Hancock and H.-G. Sahl, Nat. Biotechnol., 2006, 24, 1551-1557.

8 M. Zasloff, Nature, 2002, 415, 389-395.

9 K. M. O'Connell, J. T. Hodgkinson, H. F. Sore, M. Welch, G. P. Salmond and D. R. Spring, Angew. Chem., Int. Ed., 2013, 52, 10706-10733.

10 E. Porter, X. Wang, H. Lee, B. Weisblum and S. Gellman, Nature, 2000, 405, 298.

11 S. Fernandez-Lopez, H.-S. Kim, E. C. Choi, M. Delgado, J. R. Granja, A. Khasanov, K. Kraehenbuehl, G. Long, D. A. Weinberger and K. M. Wilcoxen, Nature, 2001, 412, 452-455.

12 M. F. Ilker, K. Nüsslein, G. N. Tew and E. B. Coughlin, J. Am. Chem. Soc., 2004, 126, 15870-15875.

13 K. Lienkamp, A. E. Madkour, A. Musante, C. F. Nelson, K. Nusslein and G. N. Tew, J. Am. Chem. Soc., 2008, 130, 9836-9843.

14 K. Lienkamp, K. N. Kumar, A. Som, K. Nüsslein and G. N. Tew, Chem.-Eur. J., 2009, 15, 11710-11714.

15 R. Liu, X. Chen, S. Chakraborty, J. J. Lemke, Z. Hayouka, C. Chow, R. A. Welch, B. Weisblum, K. S. Masters and S. H. Gellman, J. Am. Chem. Soc., 2014, 136, 4410-4418.

16 K. Kuroda and G. A. Caputo, Wiley Interdiscip. Rev.: Nanomed. Nanobiotechnol., 2013, 5, 49-66.

17 I. Sovadinova, E. F. Palermo, M. Urban, P. Mpiga, G. A. Caputo and K. Kuroda, Polymers, 2011, 3, 1512-1532.

18 J. C. Tiller, in Bioactive surfaces, Springer, 2010, pp. 193-217. 19 L. Timofeeva and N. Kleshcheva, Appl. Microbiol. Biotechnol., 2011, 89, 475-492.

20 K. Kuroda and W. F. DeGrado, J. Am. Chem. Soc., 2005, 127, 4128-4129.

21 R. Liu, X. Chen, Z. Hayouka, S. Chakraborty, S. P. Falk, B. Weisblum, K. S. Masters and S. H. Gellman, J. Am. Chem. Soc., 2013, 135, 5270-5273.

22 T. Eren, A. Som, J. R. Rennie, C. F. Nelson, Y. Urgina, K. Nüsslein, E. B. Coughlin and G. N. Tew, Macromol. Chem. Phys., 2008, 209, 516-524.

23 Y. Xue, H. Xiao and Y. Zhang, Int. J. Mol. Sci., 2015, 16, 36263655.

24 A.-G. Xie, X. Cai, M.-S. Lin, T. Wu, X.-J. Zhang, Z.-D. Lin and S. Tan, Mater. Sci. Eng., B, 2011, 176, 1222-1226. 
25 T. Wu, A.-G. Xie, S.-Z. Tan and X. Cai, Colloids Surf., B, 2011, 86, 232-236.

26 L. Wang, X. Xu, S. Guo, Z. Peng and T. Tang, Int. J. Biol. Macromol., 2011, 48, 375-380.

27 S. Kurata, N. Hamada, A. Kanazawa and T. Endo, Dent. Mater. J., 2011, 30, 960-966.

28 L. L. Kiessling and R. M. Owen, Handbook of Metathesis: Catalyst Development, 2003, pp. 180-225.

29 M. R. Buchmeiser, Chem. Rev., 2000, 100, 1565-1604.

30 T. M. Trnka and R. H. Grubbs, Acc. Chem. Res., 2001, 34, 1829.

31 K. Lienkamp and G. N. Tew, Chem.-Eur. J., 2009, 15, 1178411800.

32 A. E. Madkour, A. H. Koch, K. Lienkamp and G. N. Tew, Macromolecules, 2010, 43, 4557-4561.

33 D. Smith, E. B. Pentzer and S. T. Nguyen, Polym. Rev., 2007, 47, 419-459.

34 A. Song, S. G. Walker, K. A. Parker and N. S. Sampson, ACS Chem. Biol., 2011, 6, 590-599.

35 M. B. France, L. T. Alty and T. M. Earl, J. Chem. Educ., 1999, 76, 659.

36 H. S. Bazzi and H. F. Sleiman, Macromolecules, 2002, 35, 9617-9620.

37 G. Adamová, R. L. Gardas, M. Nieuwenhuyzen, A. V. Puga, L. P. N. Rebelo, A. J. Robertson and K. R. Seddon, Dalton Trans., 2012, 41, 8316-8332.
38 J. J. Kiddle, Tetrahedron Lett., 2000, 41, 1339-1341.

39 M. Schmider, E. Müh, J. E. Klee and R. Mülhaupt, Macromolecules, 2005, 38, 9548-9555.

40 K. Stubenrauch, C. Moitzi, G. Fritz, O. Glatter, G. Trimmel and F. Stelzer, Macromolecules, 2006, 39, 5865-5874.

41 L. Fu and C. Fu-Liu, Tuberculosis, 2002, 82, 85-90.

42 P. J. Brennan and D. C. Crick, Curr. Top. Med. Chem., 2007, 7, 475-488.

43 P. J. Brennan, Tuberculosis, 2003, 83, 91-97.

44 S. H. White and W. C. Wimley, Annu. Rev. Biophys. Biomol. Struct., 1999, 28, 319-365.

45 G. J. Gabriel, A. Som, A. E. Madkour, T. Eren and G. N. Tew, Mater. Sci. Eng., R, 2007, 57, 28-64.

46 K. A. Brogden, Nat. Rev. Microbiol., 2005, 3, 238-250.

47 G. N. Tew, D. Liu, B. Chen, R. J. Doerksen, J. Kaplan, P. J. Carroll, M. L. Klein and W. F. DeGrado, Proc. Natl. Acad. Sci. U. S. A., 2002, 99, 5110-5114.

48 A. Som, A. Reuter and G. N. Tew, Angew. Chem., Int. Ed., 2012, 51, 980-983.

49 B. M. deRonde, A. Birke and G. N. Tew, Chem.-Eur. J., 2015, 21, 3013-3019.

50 C. S. Alves, M. N. Melo, H. G. Franquelim, R. Ferre, M. Planas, L. Feliu, E. Bardají, W. Kowalczyk, D. Andreu and N. C. Santos, J. Biol. Chem., 2010, 285, 27536-27544. 